\title{
Russian And United States Graduate Business Students Differ In Their Ethical Beliefs
}

Paul Mihalek, Central Connecticut State University, USA

Anne Rich, Central Connecticut State University, USA

John Speir, The American Institute of Business and Economics, USA

\begin{abstract}
Russia, once isolated from the Western world, is now encouraging trade and direct investment. Currently, there is substantial interest by foreign investors, including those in the U.S., to invest in Russian enterprises. The increasing globalization of business, in general, and specifically with Russia, requires managers to develop a better understanding of the cultural background and ethical reasoning of the individuals who are involved in multinational business. This paper presents the results of a research study comparing Russian graduate business students with U.S. graduate business students. Survey questions were used to obtain responses related to five business activities. The purpose of this study was to identify whether there are differences in the ethical beliefs of graduate business students in Russia and the United States. Predications of the responses were based on the four cultural dimensions delineated by Hofstede. The questions asked replicated the study conducted by Nyaw and $\mathrm{Ng}$ (1994) and the statistical analysis includes a discussion on outlier and bracketing effects. Our study shows differences between Russian and U.S. graduate business students in ethical behavior in the areas of job security, health and safety, tolerance for unethical behavior towards customers and suppliers and toward business rivals. However, the differences are not always predicable based on Hofstede's theories.
\end{abstract}

Keywords: Russian students, Business students, student attitudes business ethics, questionnaires

\section{INTRODUCTION}

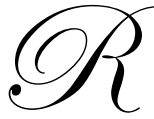

ussia, once isolated from the Western world, is now encouraging trade and direct investment. As Exhibit1 reveals, there has been a substantial interest by countries other than the U.S. to invest in Russia. The chart also demonstrates that while U.S. investment accounted for only 6.7 percent of total foreign investment in Russia in 2006, the interest from U.S. investors has more than doubled since 2005.

Exhibit 2 demonstrates the growing amount of imports from Russia to the U.S. and the slightly increasing exports from the U.S. to Russia. We expect this trend to continue to grow. U.S. managers will have an everincreasing interaction with Russian managers, and Russian managers will have an ever-increasing interaction with their American counterparts. The U.S. Foreign Corrupt Practices Act of 1977 holds U.S. managers accountable for ethical behavior when dealing with foreign countries. The increasing globalization of business, in general, and specifically with Russia, requires managers to develop a better understanding of the cultural background and ethical reasoning of the individuals who are involved in multinational business. Cohen, Pant and Sharp (1996) indicate the importance for multinational accounting firms to predict international differences in ethical behavior. Their research supports the popular belief that Hofstede's (1980) original four measures of national culture are useful for designing studies that investigate cross-national differences in ethical sensitivity and offer several suggestions to improve the usefulness of research results. Only a few cross-national ethics studies have focused on the differences in ethical beliefs between Eastern Europeans and nationals of other countries. 
Exhibit 1: Foreign Investment in Russia by Source

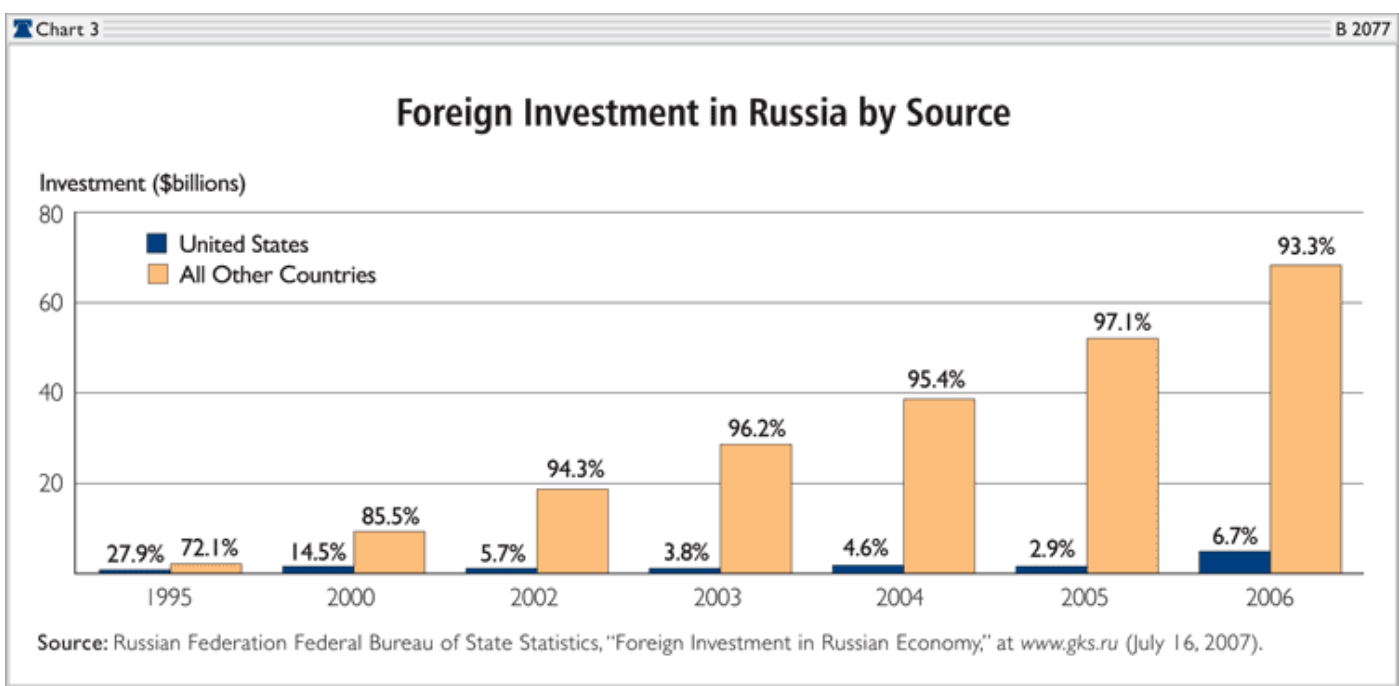

(source: http://www.heritage.org/research/russiaandeurasia/images/b2077_chart1-lg.gif

Exhibit 2: U.S. Russian Bilateral Trade

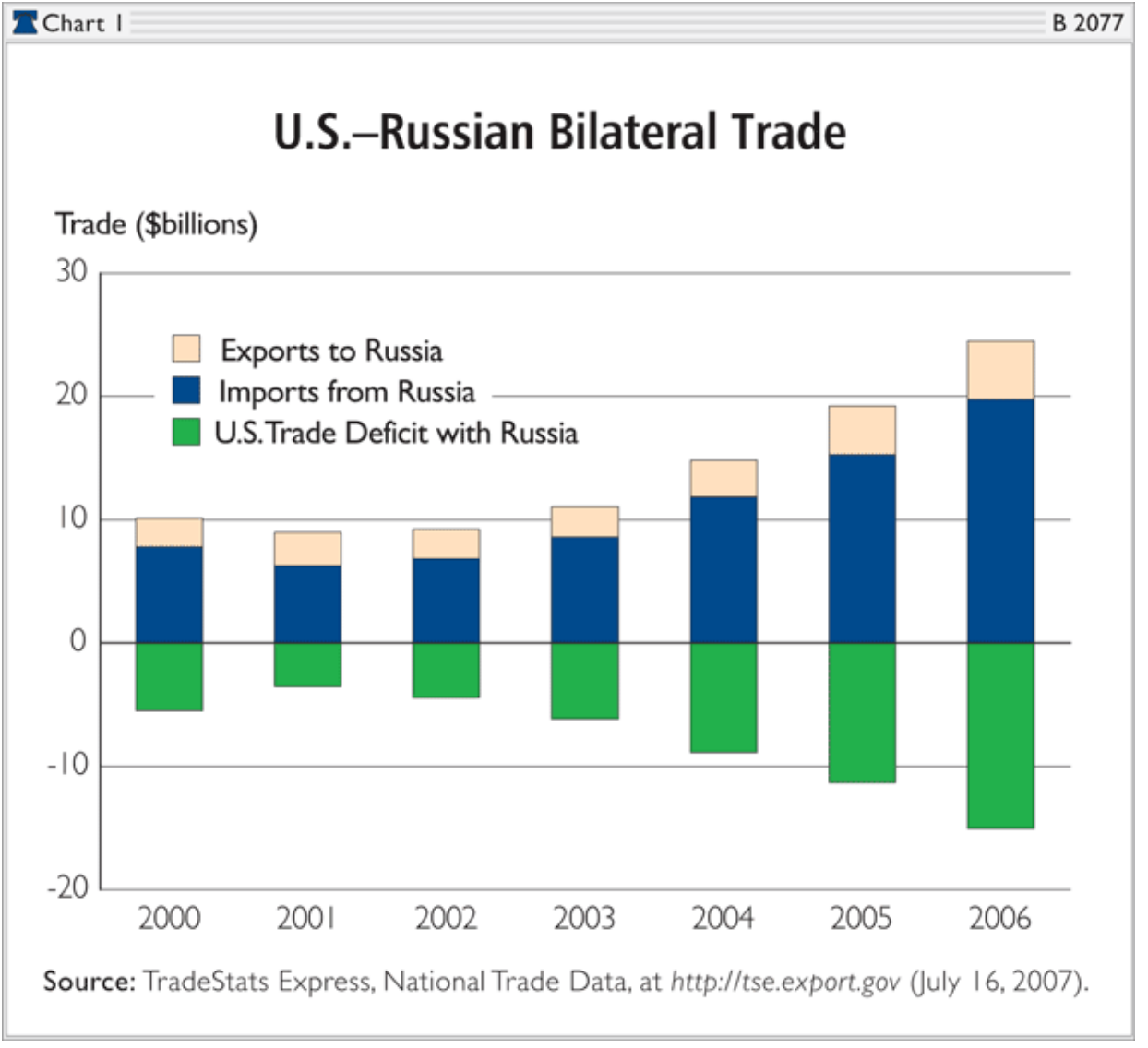

(found at: http://www.heritage.org/research/russiaandeurasia/images/b2077_chart1-lg.gif) 
As a basis for this survey, we used an instrument designed by Nyaw and $\mathrm{Ng}$ (1994). It was a comparative analysis of the ethical beliefs of business students from four countries: Canada, Japan, Hong Kong, and Taiwan. Their study was unique in that it measured the respondents' ethical beliefs toward five stakeholder groups, as developed by Waters et. al. (1986). Nyaw and Ng developed five major hypotheses based on Hofstede's 1983 study in which he identified four cultural dimensions (individualism-collectivism, masculinity-femininity, power-distance, and uncertainty-avoidance). Nyaw and $\mathrm{Ng}$ then used this information to develop a series of ethical situations reflecting the five stakeholder groups and the four cultural dimensions. The empirical results of their study indicated that while national origin may impact individuals' reactions to particular ethical dilemmas, Hofstede's model is somewhat limited in predicting ethical beliefs across nations.

The Nyaw and Ng study tested Asians from Hong Kong, Japan and Taiwan, and only later was testing performed on individuals from mainland China. Additional studies were conducted with European subjects from the late 80 's through the current period. We believe that there could be differences in study results if the study were replicated with subjects from Russian and United States graduate business students.

\section{Purpose}

The purpose of this study is to identify whether there are differences in the ethical beliefs of graduate business students in Russia and the United States when compared to using the four dimensions delineated by Hofstede. This study replicates the study conducted by Nyaw and $\mathrm{Ng}$ (1994). Earlier studies have compared United States business students with students from France and Germany (Becker, et. al., 1987), Israel (Preble and Rachel, 1988), Denmark and New Zealand (Lysonski and Gaidis, 1991), South Africa (Orpen, 1987), and Nigeria (Tsalikis and Nwachukwu, 1991).

\section{Business Ethics in Literature}

Defining ethics has been problematic for both practitioners and researchers (Brenner; Molander 1977). Although several definitions have been proposed, the elements which ethics encompass; i.e., moral principles and standards, provide the basis for the paper. Ethical research has evolved and proliferated over the last twenty years. The earlier research focused on domestic ethical issues. In the last decade, there has been increasing emphasis on cross-cultural ethics. The topics range from corporate codes of ethics (Langlois and Schlegelmilch 1990) to bribery (Tsalikis and Nwacaukwu, 1992). Ralston states that "one of these under-explored areas of particular relevance in today's global economy is the issue of differences in ethics across cultures." Studies are currently beginning to address these issues. For example, Khazanchi (1995) reports that "on the average, there is a significant gender gap in the recognition of unethical behavior in information systems." He stated that women outperformed men in identifying unethical actions. This supports studies of Armstrong (1987), Lampe and Finn (1992) and St. Pierre, et al (1990) who found accounting students to have low levels of ethical reasoning. In the latter, they found that female accounting majors have higher ethical scores than males. Conversely, Sikula's 1994 study of a large sample of California State University college-aged students does not support the forgoing hypothesis. Consequently, review of gender issues research indicates the need for further study.

Sommer, Welsh and Gubman (2000) studied the ethical orientations of Russian entrepreneurs. They selected entrepreneurs because Russian small private businesses led privatization and economic transformation. The researchers used a model for identifying ethical orientation that classified individuals on two dimensions - idealism and relativism. The former accepts only right behaviors leading to right outcomes, while the later accepts the "ends justifies the means" theory. They compared their survey results to U.S. entrepreneurs. Citing Russia as a collectivist culture where close personal friendships are important, the researchers recognized that the people-relationship impact is a primary emphasis in Russian decision making. Their results suggested that building relationships occurs prior to successful joint ventures. Specifically, they state that "a careful inspection of our results shows the cultural difference to follow a specific and peculiar pattern". That is, while the Russian entrepreneurs were eager to engage in behavior that exploited opportunities, they nevertheless were protective of our personal relationships with business associated. The conclusion of Sommer et al supports the notion that cultural influences interact with situational factors. 
Culture has been considered a significant research topic since the 1980s. Hofstede, throughout the 1980's, developed a framework of culture that provides an assessment of the extent to which cultures differ from each other (Nyaw and $\mathrm{Ng}$ ). Hofstede defines culture as "a collective mental programming that consists of four dimensions: individual-collectivism, masculinity-femininity, power-distance, and uncertainty-avoidance.” (Nyaw) In Hofstede's 1980 study, he categorized the major cultural dimensions for each of forty countries, using a range of 0 to 100 . Unfortunately, Russia was not included in Hofstede's IBM study. However, Welsh, et al conducted a survey of Russian engineers in the late 1980's. The results of their study ranked Russians high in power-distance. Concerning the uncertainty-avoidance characteristic, the researchers felt that since Russia respects long-term relationships and values stability, it would be high in this dimension as well. Russia has traditionally been a collectivist society for the past three hundred years and is so designated in this dimension, even though the breakup of the former Soviet Union has changed their political situation. In Hofstede's model, Russia can be considered included in the group of developing countries while the U.S. belongs to the Anglo class for the masculine-feminine dimension. Differences on the four dimensions are suggested by the researchers to be as follows:

$\begin{array}{lll}\text { Hofstede's Characteristics } & \underline{\text { Russia }} & \underline{\text { United States }} \\ \text { Power-distance } & \text { high } & \text { low/medium } \\ \text { Uncertainty-avoidance } & \text { high } & \text { low / medium } \\ \text { Individualism-collectivism } & \text { collectivist } & \text { individualist } \\ \text { Masculine-feminine } & \text { low/medium } & \text { high }\end{array}$

In the past, Russian business ethics have not been perceived as very high. The business climate around the year 2002 revealed several major business frauds. Vadi and Jaakson (2006) state that "modern managers of the companies with Soviet history have admitted that the biggest challenge in their managerial career has been changing employees' attitudes toward stealing company's assets".

Kliucharev and Muckle (2005) explored the complexity, or possible confusion, in public attitudes to ethical issues in Russia. They describe the "Soviet person" being impacted by the mass media, the world of business, and the Church . However, these three influences are seen as promulgating conflicting values. Thus, while business is becoming an important source of moral values, they conclude that Russians have not yet reconciled the traditional Russian community spirit with the spirit of enterprise. Another research study supports the slow, but nevertheless, changing nature of traditional Russian business values. Lundlum and Moskaloinov (2005) discuss the emerging former soviet economic transition to private business. In their paper, the authors indicate that ethics problems are commonplace in Russian business. They conducted a study of Russian business students around the same time as our study. Their research examined Russian business students' attitudes towards business ethics. Some of their subjects had taken a course in business ethics. Their research results indicated overwhelmingly that Russian business students did not want to work for an unethical company. However, they also cautioned as Russia transitions to a more global economy, Russian business owners will not simply follow Western notions of business.

As a result of increased participation in the world economy, the situation in Russia will likely change, even more than in the early years of the $21^{\text {st }}$ century. There is some research to support that Russians are beginning to accept the Western model of behavior in the corporate world. For example, McCarthy and Puffer (2008) cite the influence of the Russian 2002 Federal Commission for the Securities Market in Russia Promulgated the Code of Corporate Conduct. This document set out the requirement for companies having more than 1,000 shareholders to be in compliance with the objectives, policies, and reporting procedures of the country's new corporate governance system. The researchers also point out that the code reflects standards developed by international bodies, such as the Organization of Economic Cooperation and Development (OECD) and the World Bank as organizations currently influencing current Russian business ethics. Since the Russian Code of Conduct applies only to large businesses, McCarthy and Puffer highlight the impact of the code will not filter down to small and medium businesses in the near future. The authors state that in Russia today, there are Western ethical influences in the business environment. Russian managers will continue to be influenced by traditional Russian norms and behaviors. As a result, the researchers warn us that Russian managers may behave in a way that is interpreted as unethical by the Western community. 
In the world of accounting, business ethics are always at the forefront. The International Federation of Accountants (IFAC), an organization whose objective is to develop and enhance worldwide accountancy, published a Code of Ethics for the Professional Accountant in 1990. In the preface, the organization recognized that there is a wide cultural diversity throughout the world in which the accountancy profession operates. The basic premise of the Code is that "in order to achieve the objectives of the accountancy profession, professional accountants have to observe a number of prerequisites or fundamental principles". Yet, there are profound differences in ethical practices that both managers, who do business with Russian companies and accountants who audit Russian businesses, must become aware of.

\section{THE NYAW AND NG STUDY}

The Mee-Kau Nyaw and Ignace Ng study, published by the Journal of Business Ethics in 1994, examined the extent to which business students from Canada, Japan, Hong Kong, and Taiwan react differently to ethical dilemmas involving employees, supervisors, customers, suppliers, and business rivals. In this prior research study, a questionnaire was developed which contained 14 ethical dilemmas. For each scenario, students were asked to respond, on a seven - point scale, to how likely they were to behave in a certain way. In the 1994 study, the researchers also measured the inclination of the respondent to respond positively to socially desirable behaviors and negatively to socially undesirable behaviors in self-report questionnaire surveys.

The 1994 study suggested that cultural dimensions identified by Hofstede could be used to help explain why students from different countries demonstrate different ethical standards with regard to employees, superiors, customers, suppliers, and competitors. Concerning job security and health and safety, the researchers hypothesized that people from collectivist societies would view their organization as more important than those in individualistic societies. Concerning discrimination against female employees, the researchers hypothesized that while both power distance and individualism could contribute to attitudes towards females, masculine societies are more inclined to resort to discriminatory practices. Concerning whistle-blowing, power distance and individualism/collectivism would be significant factors causing differences between groups. If there were high respect for authority (high power distance), as well as high loyalty to the group (collectivist), employees would be more inclined to cover for their superior's questionable activities.

The researchers also thought the uncertainty-avoidance dimension would explain inter-country differences in behaviors toward customers and suppliers. Strong uncertainty- avoidance countries, which have a preference for stability and consistency, would put great emphasis in maintaining their relationships with existing customers and suppliers. As a result, strong uncertainty avoidance countries would be less tolerant of unethical behaviors toward customers and suppliers. Finally, in collectivist countries where group loyalty is intense, group members would be more willing to engage in unethical practices to outperform business rivals. On the other hand, individualistic countries would be less willing to engage in such practices. Also contributing to treatment of rivals is the masculinefeminine dimension. In masculine societies, performance is highly valued where the "end justifies the means". Thus, the researcher felt that highly masculine societies are more likely to engage in unethical behavior in order to beat business rivals.

\section{HYPOTHESES}

For the purpose of this study, the major implication of Hofstede's framework is that the groups of U.S. and Russian business students differ from each other in the four cultural dimensions identified previously. Thus, we would expect differences in responses of Russian graduate business students and U.S. graduate business students when faced with ethical dilemmas.

The characteristics for power-distance, individualism and masculinity, as well as the arguments made in the original study by Nyaw and $\mathrm{Ng}$, formed the basis for the five hypotheses that we developed in this study. These hypotheses are: 
Since the U.S. is considered to be highly individualistic and Russia is collectivist, it can therefore be hypothesized that:

H1: When compared to Russians, the U.S. respondents are less likely to show concern for the job security and/or health and safety of employees.

that:

Since the U.S. is a perceived to be a more masculine society than Russia, it can therefore be hypothesized

H2: Of the two countries, the U.S. is more likely to be tolerant of discriminatory practices against females.

Since the U.S. scores are low on high power-distance compared to our perception of Russia, it is hypothesized that:

H3: Of the two countries, the U.S. is less likely to accept questionable practices by supervisors.

Since Russia desires long-term relationships with customers and suppliers and its need for uncertainty avoidance is believed to be higher than that of the U.S., it is hypothesized that:

H4: Of the two countries, the United States is more likely to tolerate unethical behavior toward customers and suppliers than Russia.

Since the U.S. is a highly individualistic society compared to Russia where group loyalty is intense, we may conclude that in individualistic U.S., there is less willingness to resort to unethical practices to outperform business rivals than in Russia. Thus, it is hypothesized that:

H5: Of the two countries, the U.S. respondents would be more ethical toward business rivals.

\section{Sample and Descriptive Statistics}

The questionnaire was administered in 2004 to 108 students who are graduate business students at the American Institute for Business and Economics, Moscow, Russia, and to 64 graduate business management majors at the University of Hartford. Both were administered during regular class periods resulting in a one hundred percent response rate. Since the classes in Moscow in which the surveys were administered were taught in English, we believe that the students' command of the English language was more than adequate to understand and respond to the questions. The age of the respondents in Russia ranged from 21 - 50, with an average age of 25.74 years, while the U.S. respondents had a smaller range, $21-44$, with an average age of 29.55 years. Twenty-eight of the U.S. respondents were male and 31 were female (not all responded to the demographic questions). In Russia, there were 57 female respondents and 45 male (again not all responded to this question). The average level of the respondents' education in the United States was comparable to that of the Russian students as shown in Exhibit 3:

\section{Exhibit 3: Education}

Level of Education
Bachelor's degree
Some graduate work
Master's degree
Ph.D. degree
Other

Level of Education

Bachelor's degree

Master's degree

Other

\begin{tabular}{lc} 
U.S. Students & Russian Students \\
\hline 16 & 32 \\
1 & 5 \\
33 & 55 \\
4 & 6 \\
1 (medical doctor) &
\end{tabular}

In terms of months of experience, the U.S. students averaged 67.67 months with a range of zero to 156 months. Russian students averaged 45.49 months with zero to 300 months of experience. In assessing the ease of 
answering the questions and the realistic nature of the questions, U.S. students responses averaged 2.446 (relatively easy) and 4.357 (moderate), respectively, whereas the Russian students averaged 2.92 and 4.887, respectively. We group the responses by hypothesis, based upon the relationships between the stakeholder and the questions as follows:

\section{Classification of Questions by Major Category}

\section{Hypothesis 1}

Questions 10 and 14 are concerned with health and safety.

Questions 2 and 11 are concerned with job security.

\section{Hypothesis 2}

Questions 4 and 7 are concerned with gender-discriminatory practices.

\section{Hypothesis 3}

Questions 6 and 9 are concerned with accepting questionable practices by supervisors.

\section{Hypothesis 4}

Questions 1 and 5 are concerned with unethical behavior towards customers.

Questions 3 and 13 are concerned with unethical behavior towards suppliers.

\section{Hypothesis 5}

Question 8 and 12 are concerned with unethical behavior towards business rivals

The data allows us to divide the respondents into Russian and U.S. respondents and into male and female respondents. We perform t-tests on the means of two aggregate groups; i.e. Russian v. U.S. and Male v. Female, and also make four comparisons of disaggregated groups; i.e. Russian Male (RM) v. U.S. Male (UM), Russian Female (RF) v. US Female (UF), Russian Male v. Russian Female, and U.S. Male v. U.S. Female. Our aggregate comparisons generate statistically significant results in six Male v. Female comparisons and nine Russian v. U.S. comparisons. Two comparisons generate statistically significant results for both aggregate comparisons and only one equation for neither. We can rank order the four disaggregated groups; i.e. Russian Males, Russian Females, U.S. Males, and U.S. Females, with a value of 1 being the most ethical response and a 4 being the least ethical response. Exhibit 4 presents these results.

Exhibit 4: Cumulative Rank Order

\begin{tabular}{|l|c|c|c|c|c|}
\hline Group/Rank & \#1s & \#2s & \#3s & \#4s & AVERAGE \\
\hline Russian Male & 2 & 2 & 4 & 6 & 3.00 \\
\hline Russian Female & 3 & 2 & 4 & 5 & 2.79 \\
\hline US. Male & 2 & 5 & 4 & 3 & 2.57 \\
\hline US Female & 7 & 5 & 2 & 0 & 1.64 \\
\hline
\end{tabular}

Based upon these results, U.S. females exhibit the most consistent ethical pattern of behavior, with Russian Males the least consistent ethical pattern of behavior. U.S. Males and Russian Females exhibit comparable frequencies of ethical behavior based upon their average ranks. In terms of rank, U.S. Females represent something of an outlier, with half of the \#1 ranks and 5 of 14 of the \#2 ranks. While U.S. Males (average rank of 2.57) have a higher rank than Russian Females (2.79), these numbers are not much different than that for Russian Males (average rank of 3.00).

We have also calculated the range of the mean responses. The largest range is 1.139 for Question 8 (Hypothesis 5, Table 5) and the smallest range is 0.346 for Question 9 (Hypothesis 3, Table 3). The only range greater than 1 is for Question 8, and 12 rangers are between 0.500 and 1.0. While statistically significant and 
important differences in behavior exist, we note that all groups tend to cluster in the relative more ethical range. The only instance in which both Russian Males and Russian Females are on one side of 3 (the neutral response) and U.S. Males and U.S. Females on the other side of 3 is Question 3 (Hypothesis 4, Table 8). In this case, the Russian responses, with a mean of 2.787, indicate relatively more ethical behavior than U.S. responses, with a mean of 3.242. If we view a value of 3, the mid-point, as being the demarcation between relatively ethical and unethical behavior, then generally, all four sub-groups tend to have means in the ethical range of behavior. With the exception of Question 3, as noted above, when a group's mean falls in the unethical range, it tends to be not much different from 3.

We need to mention two patterns that appear in the analysis. The first is what we call an 'outlier' effect. In this situation, one of the respondent groups (RM, RF, UM, or UF) exhibits a large deviation in the value of its mean relative to the other groups. This pattern is most prominent in 3 of the 4 questions in Hypothesis 1 (Questions 10, 14, and 2, Table 5). Second, we designate a 'bracketing' effect. In this case, the two groups for one country lie between the two groups for the other country. Thus, it is possible to have mean values that are very close, but which obscure underlying differences in behavior. An example of this is seen in Question 7 (Hypothesis 2, Table 6). These two patterns indicate the possible presence of a gender-country/culture interaction. This will require further analysis to determine why one respondent group might deviate from the others and why respondents from one country exhibit a much larger range in responses than the other.

In the analysis that follows, we use Excel to conduct a t-test, assuming different variances, to compare the means of Russian and U.S. respondents, and Male and Female respondents. We use the disaggregated data to conduct four comparisons of the sub-groups; i.e. RM v. RF, UM v. UF, RM v. UM, and RF v. UF. We consider each hypothesis in turn and provide a table for each hypothesis which reports the t-statistic assuming different variances, the probability associated with each t-statistic, means, variances, range of the four disaggregated group means, and rank order (in parenthesis). Each table also contains a statement of the hypothesis, each question, and whether higher values are associated with more or less ethical behavior. In our analysis, we will draw one of four conclusions. First, the hypothesis is confirmed. In this case the statistical comparison will generate t-statistics that are significant at a $10 \%$ level or better, and have the correct sign. Second, a hypothesis may not be confirmed. Here, the t-statistics do not achieve a sufficient value to be a statistically significant level. Third, we allow the hypothesis to be contradicted. To be contradicted, there must be statistical significance at a $10 \%$ level or better, but the sign is the opposite of that predicted by the hypothesis. Fourth, it is possible for there to be different results from the questions relating to the same hypothesis. In this case, we will have mixed results. Tables 1,23 and 4 provide the results of our analysis related to Hypothesis 1.

Hypothesis 1: When compared to Russians, the U.S. respondents are less likely to show concern for the job security and/or health and safety of employees.

Concerning Safety:

10- How likely are you to buy ergonomically designed tools? (higher more ethical)

14- How likely are you to purchase safety equipment? (higher more ethical)

Table 1: T Statistics and probabilities Questions 10 and 14

\begin{tabular}{|c|c|c|c|c|c|c|}
\hline Question & M v F & R v US & RM v UM & RF v UF & RM V RF & UM v UF \\
\hline 10 (t-stat) & -1.179 & $-1.454^{* *}$ & -0.347 & $-2.253^{*}$ & -0.468 & $-2.059^{*}$ \\
\hline & 0.120 & 0.074 & 0.365 & 0.015 & 0.320 & 0.023 \\
\hline & & & & & & \\
\hline 14 (t-stat) & $1.514^{* *}$ & $-3.321^{*}$ & $-3.68^{*}$ & -1.145 & 0.103 & $1.719^{*}$ \\
\hline & 0.066 & 0.0006 & 0.0002 & 0.130 & 0.459 & 0.049 \\
\hline
\end{tabular}


Table 2: Means and variances for Questions 10 and 14 and Rank in parenthesis

\begin{tabular}{|c|c|c|c|c|c|c|c|c|c|}
\hline $\mathbf{Q}$ & $\mathbf{R}$ & $\mathbf{U}$ & $\mathbf{M}$ & $\mathbf{F}$ & $\mathbf{R M}$ & $\mathbf{R F}$ & $\mathbf{U M}$ & UF & Range \\
\hline 10 & 3.583 & 3.823 & 3.575 & 3.740 & $3.500(4)$ & $3.603(2)$ & $3.588(3)$ & $4.159(1)$ & 0.659 \\
\hline Var. & 1.18 & 1.001 & 1.289 & 1.037 & 1.411 & 1.051 & 1.586 & 0.807 & \\
\hline & & & & & & & & & \\
\hline 14 & 3.583 & 4.113 & 3.913 & 3.662 & $3.609(3)$ & $3.586(4)$ & $4.324(1)$ & $3.895(2)$ & 0.738 \\
\hline Var. & 1.198 & 0.889 & 0.922 & 1.148 & 1.266 & 1.194 & 0.340 & 0.988 & \\
\hline
\end{tabular}

Concerning job security:

2 - How likely are you to run the factory for the whole year? (higher more ethical)

11- How likely are to offer retraining to displaced employees? (higher more ethical)

Table3: T Statistics and probabilities Questions 2 and 11

\begin{tabular}{|c|c|c|c|c|c|c|}
\hline Question & M v F & R v US & RM v UM & RF v UF & RM V RF & UM v UF \\
\hline 2 (t-stat) & $2.474 *$ & -0.964 & 0.735 & $-2.235^{*}$ & $3.062^{*}$ & -0.637 \\
\hline & 0.007 & 0.168 & 0.232 & 0.017 & 0.001 & 0.264 \\
\hline & & & & & & \\
\hline 11 (t-stat) & $-1.702^{*}$ & $1.421^{* *}$ & 1.159 & -0.447 & -0.942 & -1.099 \\
\hline & 0.045 & 0.088 & 0.125 & 0.329 & 0.174 & 0.139 \\
\hline
\end{tabular}

Table 4: Means and variances for Questions 2 and 11 and Rank in parenthesis.

\begin{tabular}{|c|c|c|c|c|c|c|c|c|c|}
\hline $\mathbf{Q}$ & $\mathbf{R}$ & $\mathbf{U}$ & $\mathbf{M}$ & $\mathbf{F}$ & $\mathbf{R M}$ & $\mathbf{R F}$ & $\mathbf{U M}$ & UF & Range \\
\hline 2 & 3.259 & 3.452 & 3.588 & 3.104 & $3.689(2)$ & $2.947(4)$ & $3.485(3)$ & $3.72(1)$ & 0.773 \\
\hline Var. & 1.577 & 1.563 & 1.461 & 1.542 & 1.583 & 1.336 & 1.38. & 1.743 & \\
\hline & & & & & & & & & \\
\hline 11 & 3.417 & 3.161 & 3.175 & 3.468 & $3.304(3)$ & $3.500(1)$ & $3.000(4)$ & $3.368(2)$ & 0.500 \\
\hline Var. & 1.049 & 1.588 & 1.336 & 0.989 & 1.283 & 0.886 & 1.394 & 1.357 & \\
\hline
\end{tabular}

Hypothesis 1 states that when compared to Russians, the U.S. respondents are less likely to show concern for the job security and/or health and safety of employees. Table 5 presents the results for Hypothesis 1 . Questions 10 and 14 are designed to gather information concerning employee health and safety. Question 10 deals with the purchase of ergonomic equipment, and 14 with the purchase of safety equipment. The aggregate comparison of Russian and U.S. respondents indicates that a statistically significant differences exists at a $10 \%$ level for question 10 and a $1 \%$ level for question 14 . The results are of the wrong sign and, as a consequence, contradict the hypothesis. Based on the aggregate comparison, U.S. respondents exhibit more concern for health and safety issues.

When the data is separated into the disaggregated data, a more nuanced situation arises. For Question 10, a comparison of U.S. Females (UF) to Russian Females (RF) and U.S. Males (UM) indicates that US Females are more likely to adopt ergonomically designed tools than the other respondent groups. These results are at least a 5\% level of statistical significance. With the other three groups in a narrow range, 3.500 to 3.603, U.S. Females, at 4.159, exhibit outlier behavior. Thus, for Question 10, U.S. Females have a statistically significant likelihood of exhibiting a more consistent ethical pattern of behavior.

For Question 14, U.S. Males exhibit outlier behavior. This outlier effect is large enough to generate statistically significant results for both Russian v. U.S. and Male V. Female comparisons (although we note that the RF V. UF Comparison narrowly misses statistical significance). The range for RM, RF, and UF is from 3.586 to 3.895, with U.S. Males at 4.324 and exhibiting statistically significant results at the 5\% level or better, U.S. Males exhibit outlier behavior.

Questions 2 and 11 address issues of job security. In Question 2, the results indicate that Males are more likely to keep the factory open for the year. These results are driven by an extremely low value for Russian Females, 
with a value of 2.947, while U.S. Females have the highest value, 3.72, with Russian Males at 3.689 and U.S. Males at 3.485. Russian Females exhibit statistically significant outlier behavior and, in this case, are less likely to exhibit an ethical pattern of behavior relative to the other groups. The low value for Russian Females contradicts Hypothesis 1 , though in a very qualified manner.

The results for Question 11 indicate that with respect to retraining, the hypothesis is confirmed. Female respondents and Russian respondents exhibit more consistent ethical patterns of behavior, of at least $10 \%$ levels of statistical significance. There are no outliers in this case, and the results are firm, though the range of response means is only 0.500 .

Overall, for Hypothesis 1, we have a clear contradiction for issues concerning safety, a mild contradiction for the issue of keeping the factory open for the year, but a clear confirmation for retraining of the employees. We therefore conclude that Hypothesis 1 is contradicted, with a caveat for employee retraining. Tables 5 and 6 provide the results related to the overall results for Hypothesis 2.

Hypothesis 2: Of the two countries, the U.S. is more likely to be tolerant of discriminatory practices.

Concerning gender discrimination:

4 - How likely are you to hire the female applicant? (higher more ethical)

7 - How likely are you to increase the wages of the female workers? (higher more ethical)

Table 5: T Statistics and probabilities Questions 4 and 7

\begin{tabular}{|c|c|c|c|c|c|c|}
\hline Question & M v F & R v US & RM v UM & RF v UF & RM V RF & UM v UF \\
\hline 4 (t-stat) & -0.546 & $-4.494^{*}$ & $-2.399^{*}$ & $-6.161^{*}$ & -0.462 & $-2.940^{*}$ \\
\hline & 0.293 & $6.5 \mathrm{E}-06$ & 0.009 & $1.9 \mathrm{E}-08$ & 0.323 & 0.002 \\
\hline & & & & & & \\
\hline 7 (t-stat) & $-3.251^{*}$ & -0.009 & 0.588 & -1.296 & $-1.807^{*}$ & $-3.071^{*}$ \\
\hline & 0.001 & 0.496 & 0.279 & 0.103 & 0.037 & 0.002 \\
\hline
\end{tabular}

Table 6: T Statistics and probabilities Questions 4 and 7 and Rank in parenthesis.

\begin{tabular}{|c|c|c|c|c|c|c|c|c|c|}
\hline $\mathbf{Q}$ & $\mathbf{R}$ & $\mathbf{U}$ & $\mathbf{M}$ & $\mathbf{F}$ & $\mathbf{R M}$ & $\mathbf{R F}$ & $\mathbf{U M}$ & UF & Range \\
\hline 4 & 4.083 & 4.661 & 4.225 & 4.311 & $4.000(4)$ & $4.105(3)$ & $4.545(3)$ & $4.944(2)$ & 0.944 \\
\hline Var. & 1.161 & 0.359 & 1.189 & 0.796 & 1.636 & 0.882 & 0.506 & 0.055 & \\
\hline & & & & & & & & & \\
\hline 7 & 3.676 & 3.677 & 3.388 & 3.935 & $3.422(3)$ & $3.825(2)$ & $3.273(4)$ & $4.167(1)$ & 0.894 \\
\hline Var. & 1.193 & 1.140 & 1.304 & 0.939 & 1.522 & 0.897 & 1.017 & 0.971 & \\
\hline
\end{tabular}

Hypothesis 2 states that of the two countries, the U.S. is more likely to be tolerant of discriminatory practices. Questions 4 (hiring) and 7 (pay equity) deal with this hypothesis, and the results are presented in Table 6. The results for Question 4 indicate that U.S. respondents are likely to exhibit a more ethical pattern of behavior in hiring at an extremely strong level of statistical significance, much less than $1 \%$, with neither outliers nor bracketing. Thus, for hiring, Hypothesis 2 is contradicted.

For pay equity, Females exhibit a more consistent ethical pattern of behavior than males. However, in this instance, we have bracketing. The means for Russian and U.S. respondents are virtually the same, 3.676 and 3.677, while U.S. Females have the highest value, 4.167, and U.S. males have the lowest value, 3.273. The range between U.S. Females and U.S. Males is 0.894, while the range between Russian Females and Russian Males is 0.403. Thus, for Question 7, we fail to confirm Hypothesis 2, although Females are likely to exhibit a more ethical pattern of behavior at a level of statistically significance of better than $1 \%$. Overall, for Hypothesis 2, we have mixed results. Tables 7 and 8 provide the results for Hypothesis 3. 
Hypothesis 3: Of the two countries, the U.S. is less likely to accept questionable practices of supervisors.

Concerning unethical behavior of Supervisors:

6 - How likely are you to conceal that your supervisor is claiming more money than he spent? (higher less ethical)

9 - How likely are you to reveal your plant manager's actions to top management at company headquarters? (higher more ethical)

Table 7: T Statistics and probabilities Questions 6 and 9

\begin{tabular}{|c|c|c|c|c|c|c|}
\hline Question & M v F & R v US & RM v UM & RF v UF & RM V RF & UM v UF \\
\hline 6 (t-stat) & $-1.445^{* *}$ & 0.219 & -0.573 & 0.313 & $1.458^{* *}$ & -0.424 \\
\hline & 0.075 & 0.413 & 0.284 & 0.378 & 0.074 & 0.337 \\
\hline & & & & & & \\
\hline 9 (t-stat) & 1.238 & 0.011 & 0.945 & -0.796 & $1.557 *$ & -0.256 \\
\hline & 0.109 & 0.496 & 0.174 & 0.216 & 0.061 & 0.3998 \\
\hline
\end{tabular}

Hypothesis 3 states that of the two countries, U.S. respondents are less likely to accept questionable practices of supervisors. The results for Hypothesis 3 are reported in Table 7, as measured by Questions 6 and 9. Neither question exhibits statistically significant results for comparisons of Russian and U.S. respondent groups. At first impression, there seems to be a difference in Male and Female behavior, as represented by the statistical significance for Question 6 and the near significance of Equation 9 in the Male v. Female statistics. In this situation, these results are due to variation in behavior between Russian Males and Russian Females. Russian Males exhibit the most ethical pattern of behavior in both questions, while Russian Females exhibit the least ethical pattern of behavior in both questions, thus bracketing the U.S. results. Overall, we fail to confirm Hypothesis 3.

Table 8: Means and variances for Questions 6 and 9 and Rank in parenthesis

\begin{tabular}{|c|c|c|c|c|c|c|c|c|c|}
\hline $\mathbf{Q}$ & $\mathbf{R}$ & $\mathbf{U}$ & $\mathbf{M}$ & $\mathbf{F}$ & $\mathbf{R M}$ & $\mathbf{R F}$ & $\mathbf{U M}$ & UF & Range \\
\hline 6 & 2.815 & 2.774 & 2.650 & 2.935 & $2.600(1)$ & $2.982(4)$ & $2.751(2)$ & $2.889(3)$ & 0.382 \\
\hline Var. & 1.703 & 1.161 & 1.47 & 1.587 & 1.700 & 1.768 & 1.252 & 1.046 & \\
\hline & & & & & & & & & \\
\hline 9 & 3.889 & 3.887 & 4.000 & 3.792 & $4.087(1)$ & $3.741(4)$ & $3.882(3)$ & $3.947(2)$ & 0.346 \\
\hline Var. & 1.277 & 0.921 & 0.987 & 1.219 & 1.192 & 1.353 & 0.715 & 0.830 & \\
\hline
\end{tabular}

Hypothesis 4 states that of the two countries, the U.S. respondents are more likely to tolerate unethical behavior to customers and suppliers than Russian respondents. This hypothesis can be separated into one concerning unethical behavior toward customers, Questions 1 and 5, and another concerning unethical behavior toward suppliers, Questions 3 and 13. In Question 1, we have statistically significant differences only between Males and Females at the aggregate level. Upon consideration of the results for the 4 sub-groups, we see that these results are driven by a low outlier value for Russian Males, of 2.978, with the other values in the range of 3.424 to 3.667. These results are also bracketed, with Russian Females having the highest value, 3.667. As a consequence, the results for Question 1 fail to confirm Hypothesis 4. The results for Question 5 indicate that Russians are less likely to exhibit an ethically consistent pattern of behavior at a statistical significance of less than $1 \%$. These results hold under the sub comparisons, and in the absence of bracketing or an outlier, the results for Question 5 contradict Hypothesis IV.

Questions 3 and 13 are concerned with unethical behavior toward suppliers. Question 3 exhibits high levels of statistical significance in the Russian and U.S. comparisons, at both the aggregate level and the disaggregate level. Russian respondents are less likely to change suppliers, and thus more likely to exhibit ethical behavior, with a high level of statistical significance of at least a $10 \%$ level. Question 3 is the only question in which U.S. respondents and Russian respondents are on the opposite side of three, with Russians relatively more ethical, and U.S. relatively less 
ethical. Thus, Question 3 confirms Hypothesis IV. Question 13 generates the opposite results to those of Question 3. For Question 13, U.S. respondents are more likely to exhibit a more ethically consistent pattern of behavior at both the aggregate and disaggregate levels, with a statistical significance of less than $2 \%$ at the aggregate level. Thus, Question 13 contradicts Hypothesis 4. Tables 9, 10,11 and 12 provide the results for Hypothesis 4.

Hypothesis 4: Of the two countries, the U.S. is more likely to tolerate unethical behavior to customers and suppliers than Russia.

Concerning unethical behavior towards customers:

1 - How likely are you to tell the customer about next week's sale? (higher more ethical)

5 - How likely are you to guarantee the shipment to obtain the contract? (higher less ethical)

Table 9: T Statistics and probabilities Questions 1 and 5

\begin{tabular}{|c|c|c|c|c|c|c|}
\hline Question & M v F & R v US & RM v UM & RF v UF & RM V RF & UM v UF \\
\hline 1 (t-stat) & $-2.483^{*}$ & -0.667 & $-1.688^{*}$ & 0.566 & $-2.925^{*}$ & -0.238 \\
\hline & 0.007 & 0.253 & 0.048 & 0.288 & 0.002 & 0.407 \\
\hline & & & & & & \\
\hline 5 (t-stat) & 0.433 & $3.135^{*}$ & $2.280^{*}$ & $2.235^{*}$ & 0.581 & 0.775 \\
\hline & 0.333 & 0.001 & 0.013 & 0.016 & 0.281 & 0.222 \\
\hline
\end{tabular}

Table 10: Means and variances for Questions 1and 5 and Rank in parenthesis

\begin{tabular}{|c|c|c|c|c|c|c|c|c|c|}
\hline $\mathrm{Q}$ & $\mathrm{R}$ & $\mathrm{U}$ & $\mathrm{M}$ & $\mathrm{F}$ & $\mathrm{RM}$ & $\mathrm{RF}$ & $\mathrm{UM}$ & UF & Range \\
\hline 1 & 3.38 & 3.5 & 3.188 & 3.636 & $2.978(4)$ & $3.667(1)$ & $3.424(3)$ & $3.500(2)$ & 0.698 \\
\hline Var. & 1.415 & 1.205 & 1.420 & 1.129 & 1.613 & 1.119 & 1.127 & 1.206 & \\
\hline & & & & & & & & & \\
\hline 5 & 2.963 & 2.403 & 2.828 & 2.753 & $3.089(4)$ & $2.947(3)$ & $2.515(2)$ & $2.278(1)$ & 0.811 \\
\hline Var. & 1.531 & 1.097 & 1.252 & 1.715 & 1.219 & 1.836 & 1.195 & 1.036 & \\
\hline
\end{tabular}

Concerning unethical behavior towards suppliers:

3 - How likely are you to change suppliers? (higher less ethical)

13 - How likely are you to accept this method of negotiating with suppliers? (higher less ethical)

Table 11: T Statistics and probabilities Questions 3 and 13

\begin{tabular}{|c|c|c|c|c|c|c|}
\hline Question & M v F & R v US & RM v UM & RF v UF & RM V RF & UM v UF \\
\hline 3 (t-stat) & 0.589 & $-2.605^{*}$ & $-2.094^{*}$ & $-1.433^{* *}$ & 0.131 & 0.541 \\
\hline & 0.278 & 0.005 & 0.020 & 0.081 & 0.448 & 0.296 \\
\hline & & & & & & \\
\hline 13(t-stat) & -0.936 & $2.190^{*}$ & $1.351^{* *}$ & $2.057^{*}$ & $-0,642$ & 0.096 \\
\hline & 0.175 & 0.015 & 0.090 & 0.023 & 0.261 & 0.462 \\
\hline
\end{tabular}

Table 12: Means and variances for Questions 3 and 13 and Rank in parenthesis.

\begin{tabular}{|c|c|c|c|c|c|c|c|c|c|}
\hline $\mathbf{Q}$ & $\mathbf{R}$ & $\mathbf{U}$ & $\mathbf{M}$ & $\mathbf{F}$ & $\mathbf{R M}$ & $\mathbf{R F}$ & $\mathbf{U M}$ & UF & Range \\
\hline 3 & 2.787 & 3.242 & 2.988 & 2.883 & $2.800(2)$ & $2.772(1)$ & $3.333(4)$ & $3.17(3)$ & 0.561 \\
\hline Var. & 1.197 & 1.203 & 1.278 & 1.183 & 1.073 & 1.251 & 1.354 & 0.971 & \\
\hline & & & & & & & & & \\
\hline 13 & 2.935 & 2.548 & 2.700 & 2.87 & $2.848(3)$ & $3.000(4)$ & $2.500(2)$ & $2.473(1)$ & 0.527 \\
\hline Var. & 1.388 & 1.137 & 1.377 & 729 & 1.554 & 1.298 & 1.106 & 0.819 & \\
\hline
\end{tabular}


Hypothesis 5: Of the two countries, the U.S. respondents would be more ethical towards business rivals.

Concerning unethical behavior towards business rivals:

8 - How likely are you to accept the plan? (higher less ethical)

12 - How likely are you to look inside your competitors' written proposals? (higher less ethical)

Table 13: t-statistics and probabilities Questions 8 and 12

\begin{tabular}{|c|c|c|c|c|c|c|}
\hline Question & M v F & R v US & RM v UM & RF v UF & RM V RF & UM v UF \\
\hline 8 (t-stat) & -0.196 & $5.257^{*}$ & $3.482^{*}$ & $2.316^{*}$ & 0.581 & 0.169 \\
\hline & 0.422 & 3.8 E-07 & 0.0005 & 0.015 & 0.281 & 0.434 \\
\hline & & & & & & \\
\hline 12 (t-stat) & -0.469 & $3.198^{*}$ & $2.555^{*}$ & $1.701^{*}$ & 0.279 & 0.434 \\
\hline & $\mathbf{0 . 3 2}$ & $\mathbf{0 . 0 0 1}$ & $\mathbf{0 . 0 0 6}$ & $\mathbf{0 . 0 4 8}$ & $\mathbf{0 . 3 9 0}$ & $\mathbf{0 . 3 3 5}$ \\
\hline
\end{tabular}

Table 14: Means and variances for Questions 8 and 12 and Rank in parenthesis

\begin{tabular}{|c|c|c|c|c|c|c|c|c|c|}
\hline $\mathbf{Q}$ & $\mathbf{R}$ & $\mathbf{U}$ & $\mathbf{M}$ & $\mathbf{F}$ & $\mathbf{R M}$ & $\mathbf{R F}$ & $\mathbf{U M}$ & UF & Range \\
\hline 8 & 4.092 & 3.016 & 3.727 & 3.766 & $4.139(4)$ & $4.017(3)$ & $3.188(2)$ & $3.000(1)$ & 1.139 \\
\hline Var. & 1.244 & 1.885 & 1.696 & 1.760 & 1.179 & 1.350 & 1.803 & 2.333 & \\
\hline & & & & & & & & & \\
\hline 12 & 2.898 & 2.258 & 2.663 & 2.766 & $2.978(4)$ & $2.897(3)$ & $2.236(1)$ & $2.368(2)$ & 0.742 \\
\hline Var. & 2.148 & 1.309 & 1.923 & 1.918 & 2.244 & 2.129 & 1.216 & 1.135 & \\
\hline
\end{tabular}

Table 15: Summary of Results

\begin{tabular}{|c|c|c|c|c|c|}
\hline Hypothesis & & Question & Result & Issue & \\
\hline \multirow{4}{*}{1} & \multirow{4}{*}{ Contradicted } & 10 & Contradicted & $\begin{array}{l}\text { Ergonomically designed } \\
\text { tools }\end{array}$ & UF outlier \\
\hline & & 14 & Contradicted & Safety equipment & UM Outlier \\
\hline & & 2 & Contradicted & Run factory whole year & RF Outlier \\
\hline & & 11 & Confirmed & Retraining & \\
\hline \multirow[t]{2}{*}{2} & \multirow[t]{2}{*}{ Mixed } & 4 & Contradicted & Hiring equity & \\
\hline & & 7 & Fail to Confirm & Wage equity & $\begin{array}{l}\text { Bracketing, US } \\
\text { larger range }\end{array}$ \\
\hline \multirow[t]{2}{*}{3} & \multirow{2}{*}{$\begin{array}{l}\text { Fail to } \\
\text { confirm }\end{array}$} & 6 & Fail to Confirm & Supervisor claiming & \multirow{2}{*}{$\begin{array}{l}\text { Bracketing, RM } 1 \\
\text { rank in both, RF } 4 \\
\text { rank in both }\end{array}$} \\
\hline & & 9 & Fail to Confirm & Supervisor polluting & \\
\hline \multirow{4}{*}{4} & \multirow{4}{*}{ Mixed } & 1 & Fail to Confirm & Next weeks sale & $\begin{array}{l}\text { Bracketing and } \\
\text { outlier low RM }\end{array}$ \\
\hline & & 5 & Contradicted & Guarantee shipment & \\
\hline & & 3 & Confirmed & Change Suppliers & \\
\hline & & 13 & Contradicted & Negotiating Method & \\
\hline \multirow[t]{2}{*}{5} & \multirow[t]{2}{*}{ Confirmed } & 8 & Confirmed & Competitors plan & \\
\hline & & 12 & Confirmed & Look inside proposal & \\
\hline
\end{tabular}


Hypothesis 5 states that of the two countries, the U.S. respondents would be more ethical toward business rivals. Questions 8 and 12 are used to gauge these differences. These results are reported in Table 9. These results indicate that U.S. respondents exhibit a greater likelihood of an ethical pattern of behavior using both aggregate and disaggregate data in both questions, and with a level of statistical significance of 5\% or better. Hypothesis 5 is confirmed. Tables 13 and 14 provide the results for Hypothesis 5. Table 15 provides the summary of our results.

\section{DISCUSSION}

\section{Health and Safety}

Based on Hofstede's four characteristics of power-distance, uncertainty avoidance, individualismcollectivism and masculine-feminine, we predicted Russian graduate students would differ from U.S. graduate students in the areas of job security, discriminatory practices against females, accepting questionable practices by supervisors, tolerating unethical behavior towards customers and suppliers, as well as being ethical toward business rivals. Our first hypothesis examined the respondents' answers to two questions related to health and safety and job security. We predicted that when compared to Russians, the U.S. respondents would be less likely to show concern for the job security and/or health and safety of employees. The results contradicted the hypothesis. Thus, U.S. respondents exhibited more concern for health and safety issues than their Russian counterparts. When dealing with health and safety, individualism-collectivism alone cannot predict responses of U.S. and Russian students. Rather, it appears the emphasis in US society on health and safety takes on a more prominent role in U.S. students' compassion for fellow employees.

In our study, we then looked at the responses based on gender differences. Our analysis revealed US females, overall, were the most ethical while Russian Males were the least ethical. U.S. Males and Russian females exhibited comparable frequencies of ethical behavior. Many prior studies on gender find that females tend to be more ethical than male students (references form Lunlum and Moskaloinov). Lunlum and Moskaloinov's research shows some support for this pattern as it applies to Russian and US students. However, our research shows some differences in ranking; specifically from most ethical to least ethical, we ranked U.S. females (most ethical), U.S. males, Russian females and Russian males (least ethical). For Hypothesis 1, dealing with health and safety of fellow employees, we found support differences among females and males. US females were more willing to adopt ergonomically designed tools, while U.S. males were more willing to purchase safety equipment. When answering questions about job security, males were more likely to keep a factory open for a year. For this question, Russian females were the least likely to keep the factory open, and there were significant differences between Russian females and U.S. females. As a result of the low values associated with the Russian females, Hypothesis 1 was contradicted. The fourth question relating to health and safety and job security provided difference results. Female respondents and Russian respondents exhibited more consistent ethical patterns of behavior when answering how likely are they to offer retraining to displaced employees. When all four health and safety/job security questions are taken as a whole, we cannot say that U.S. respondents are consistently less likely to show concern as compared to their Russian counterparts. Rather, we can conclude that there are differences based on situations dealing with specific issues, such as safety issues and retraining.

\section{Tolerance of Discriminatory Practices}

We predicted that of the two countries, the U.S. is more likely to be tolerant of discriminatory practices. We asked two questions related to hiring and pay equity of female workers. Overall, the research results were mixed. US respondents were statistically more likely to exhibit a more ethical pattern of behavior in hiring, however, there was no overall difference between U.S. and Russian respondents in answering the pay equity question. There were, however, gender differences as expected. Females exhibited a pattern of more ethical behavior than males and U.S. females provided the highest ethical scores.

\section{Acceptance of Questionable Practices}

We predicted that of the two countries, the U.S. would be less likely to accept questionable practices of 
supervisors. We asked two questions related to concealing lies by a supervisor and revealing to top management unethical actions by a supervisor. The results show no significant differences between U.S. and Russian respondents. When gender was considered, it was interesting to see variations in Russian males and Russian females. Russian males exhibited the most ethical pattern of behavior and Russian females exhibited the least ethical pattern.

\section{Tolerance of Unethical Behavior Towards Customers and Suppliers}

We predicted that the U.S. respondents are more likely to tolerate unethical behavior toward customers and suppliers than Russian respondents. We asked four questions; two related to interactions with customers and two related to interactions with suppliers. Overall, the results were contradicted. Once again, gender differences shed some light on the results. Russian males provided the least ethical responses while Russian females provided the most ethical responses.

The results in this category should also be considered in relation to differences between interactions with suppliers and customers as two separate groups. When isolating the two questions related to customers, Russian respondents appear somewhat less likely to exhibit an ethically consistent pattern of behavior toward customers. However, when examining the results related to tolerance of unethical behavior toward suppliers, we obtained inconsistent results. Russian respondents were less likely to change suppliers and thus, more likely to exhibit ethical behavior. The opposite conclusion was derived from responses to the question relating to how likely the individual was to accept a specific method of negotiating with suppliers. The responses to this question indicated that U.S. respondents were more likely to exhibit a more ethically consistent pattern of behavior.

\section{Tolerance of Unethical Behavior Towards Business Rivals}

We predicted that of the two countries, U.S. respondents would be more ethical toward business rivals. We asked two questions related to accepting a specific plan and looking at a competitor's proposals. The results indicated that U.S. respondents exhibited a greater likelihood of an ethical pattern of behavior than their Russian respondents.

\section{LIMITATIONS OF THE STUDY}

There are several factors that may limit our findings. First, unlike Nyaw and $\mathrm{Ng}$, we did not control for social desirability response bias. In addition, Russia was not included in the original Hofstede study. As a result, there are no scores for Russia for the four cultural dimensions identified by Hofstede. The ones which we assigned may not be totally representative. However, neither of these limitations diminishes the relevance of the statistical analysis, nor do they invalidate differences in response to specific questions that we identify.

Another limitation may be that the 14 situations are not the best ones to use when drawing conclusions about unethical behaviors toward the five stakeholder groups. As Cohen, Pant and Sharp (1996) explain, a vignette is likely to be useful to cross-cultural researchers if: 1) it identifies cross-culturally relevant issues and 2) it is reliable. It is possible that the vignettes used in the study were unable to identify important cross-cultural differences. Indeed, we accept this as probable and an inherent limitation of the 14 vignettes utilized in our study. Future research will be needed to develop new vignettes that allow a more complete understanding of differences between Russian and U.S. respondents.

Several other issues can also limit our findings. The Russian students answered the questionnaire in English. While we have a high degree of confidence in the English abilities of the Russian respondents, and while each situation was explained, it is possible that the question was not fully understood. Another issue is that, as in all such studies, actual behaviors in the workplace may be different from the students' responses. In addition, other factors such as age, work experiences, and legal environment, as well as a host of demographic factors such as marital status, religion and children, may influence responses. Finally, when more than one cultural dimension is considered, it is difficult to predict behaviors. Multivariate analysis should be utilized to learn about the trade-offs between the four dimensions. 
While there are undoubtedly differences between Russian and U.S. respondents, it is important to remember that Russians have come from under communism, through the chaos of the crony capitalism of the Yeltsen/Putin years, to what the system is currently evolving. In these circumstances, self-preservation may trump ethical behavior. As a consequence, the Russian responses should be viewed in this light.

Lastly, changes in the world's economic conditions, as well as the influences of western businesses in Russia, may have a significant impact on the ethical beliefs of both U.S. and Russian individuals in the future.

\section{CONCLUSION}

The study of ethical practices in business situations is complex. As businesses engage in global activities, clearly there will be a confluence of factors that impact individual decisions with respect to job security, health and safety, tolerant of female practices, questionable practices of supervisors, unethical behavior toward suppliers and customers, as well as business rivals. Individual behavior is impacted by many variables, including religion and culture. Through the use of the internet and other modern technologies, cultures are quickly being blended. Our study highlights how difficult it is to predict human behavior.

There are several contributions of our study to the literature. First, there have been very few studies of ethical behavior written in English. Our study provides another early look at Russian business ethics. Second, our study demonstrates that hypothesis testing should consider outlier and bracketing effects. Finally, our study shows differences in ethical behavior in the areas of job security, health and safety, tolerance for unethical behavior toward customers and suppliers and toward business rivals. However, the differences are not always predicable based on Hofstede's theories. Human resource managers may want to use these types of situational dilemmas to obtain information about how prospective and current employees would resolve ethical dilemmas likely to be found in their workplace.

Future research should include longitudinal studies to observe how Russian and U.S. subjects change their ethical beliefs over time. The impact of corporate codes of ethics, as well as training in ethics, should also be studied. In addition, Russia, as well as the U.S., both have diverse demographic groups which may provide additional insight into differences between the groups.

As more and more western companies do business with Russian enterprises, there will likely be a convergence of practices. However, at this point in time, there are some differences and western managers should be aware of the divergence of thought between their U.S. employees and their Russian counterparts

\section{AUTHOR INFORMATION}

Paul Mihalek, Ph.D., CPA, CMA is professor of accounting at Central Connecticut State University. His research interests include business ethics and, developing students' critical thinking. He speaks Russian and has visited Russia many times.

John Speir, Ph.d. teaches Managerial Economics and Operations Management at the American Institute of Business and Economics. . He worked in Russia from 1994 to 1998 and has returned to the country many times. He has taught at Moscow University-Touro. His Russian courses have included Business and Society, Ethics, Macroeconomics and Finance.

Anne Rich, Ph.D., CPA, CMA is professor of accounting at Central Connecticut State University. Her research interests include international accounting, business ethics and developing students' critical thinking skills.

\section{REFERENCES}

1. Armstrong, R. W. and J. Sweeney:1994, Industry Type, Culture, Mode of Entry and Perceptions of International Marketing Ethics Problems: A Cross Cultural Comparison. Journal of Business Ethics 13(10): 775-785. 
2. Becker, H. and D. J. Fritzsche: 1987,. Business Ethics: a Cross-cultural Comparison of Managers' Attitudes. Journal of Business Ethics 6:(4) 289-295.

3. Brenner, S. N. and E. A. Molander: 1977,. Is the Ethics of Business Changing? Harvard Business Review 55(1): 55-71.

4. Cohen, J.R., L. Pant and D. Sharp: 1996, A methodological Note on Cross Cultural Accounting Ethics Research, International Journal of Accounting, 31:55-66

5. Kliucharev G. and J.Muckle: 2005., Ethical Values in Russian Education Today: A moral Maze Journal of Moral Education Vol; 34 (4) 465-477

6. Hofstede, G:: 2001, Culture's Consequences $2^{\text {nd }}$ edtion (Sage Publications, Beverly Hills).

7. Hofstede, G.: 1980, Culture's Consequences (Sage Publications, Beverly Hills).

8. Hofstede, G.: 1983,. The Cultural Relativity of Organizational Practices and Theories. Journal of International Business Studies 14(2): 75-89.

9. Hofstede, G., B. Neuijen, D. Daval D. Ohayv and G. Sanders: 1990, Measuring Organizational Cultures: a Qualitative and Quantitative Study Across Twenty Cases. Administrative Science Quarterly 35(2): 286316.

10. Khazanchi, D.: 1995, Unethical Behavior In Information Systems: The Gender Factor. Journal of Business Ethics 14(9): 741-749.

11. Lampe J. and D. Finn: 1992, A Model of Author's Ethical Decision Process. Auditing: A Journal of Practice and Theory 11(Supplement): 33-59.

12. Langlois, C. C. and B. B. Schlegelmilch:: 1990, Do Corporate Codes Reflect National Character? Evidence from Europe and the United States. Journal of International Business Studies 21: 519-539.

13. Lundlum M.P, and S. Moskaloinov: 2005, Russian Student Views on Business Ethics - Post Enron College Student Journal 39(1) 156-165

14. Lysonski, S. and G, William:: 1991, A Cross-Cultural Comparison of the Ethics of Business Students, Journal of Business Ethics 10(2): 141-150.

15. McCarthy, D.J.. and S.M.. Puffer: 2008, Interpreting the Ethicality of Corporate Governance Decisions in Russia : Utilizing Integrative Social Contracts Theory to Evaluate the Relevance of Agency Theory Norms, Academy of Management Review, 33 (1) 11-31

16. Nyaw, M and I. Ng: 1994, A Comparative Analysis of Ethical Beliefs: A Four Country Study. Journal of Business Ethics 13(7): 543-555.

17. Orpen, C: 1987, The Attitudes of the United States and South African Managers to Corporate Social Responsibility, Journal of Business Ethics 6(2) 89-96

18. Preble J. and A. Reichel: 1988,: Attitudes Towards Business Ethics of Future Managers in the U. S. and Israel, Journal of Business Ethics 7(12): 941-949.

19. Ralston, D. A., R. A. Giacalone and R. H. Terpstra: 1994, Ethical Perceptions of Organizational Politics: A Comparative Evaluation of American and Hong Kong Managers. Journal of Business Ethics 13(12): 989999.

20. Sikula, Sr., A and A. D. Costa: 1994, Are Women More Ethical Than Men? Journal of Business Ethics 13(11): 859-871.

21. Sommer, S, D.Welsh and B. Gubman: 2000, The Ethical Orientation of Russian Entrepreneurs, Applied Psychology: An International Review 49(4) 688-703

22. St. Pierre, K. E., E. S. Nelson and A. L. Gabbin: 1990,. A Study of the Ethical Development of Accounting Majors in Relationship to Other Business and Nonbusiness Disciplines. The Accounting Educators' Journal 3: 23-35.

23. Tsalikis, J. and O. Nwachukwu:: 1991, A Comparison of Nigerian to American Views of Bribery and Extortion in International Commerce, Journal of Business Ethics 10(2): 85-98.

24. Vadi, M. and K. Jaakson: 2006, The Importance of Value Honest: Determining Factors and Some Hints to Ethics University of Tartu - Faculty of Economics \& Business Administration Working Paper Series 3(33)

25. Waters, J. A., F. Bird and P. D. Chant: 1986, Everyday Moral Issues Experienced by Managers. Journal of Business Ethics, 5(3): 373-384.

26. Welsh, D. H. B., Luthans F., and Sommer, S.M: 1993,. Managing Russian Factory Workers: The Impact of US-Based Behavioral and Participative Techniques. Academy of Management Journal, 36, 58-79.

27. URLs http://www.heritage.org/research/russiaandeurasia/images/b2077 chart1-lg.gif 


\section{APPENDIX I}

\section{QUESTIONS USED IN THE STUDY}

This questionnaire was developed by Mee-Kau Nyaw and Ignance $N g$ and included in their article "A Comparative Analysis of Ethical Beliefs: A Four Country Study" published by the Journal of Business Ethics, July 1994.

1. You are a sales representative for a photocopier firm. A client approaches you to purchase a used copy machine. You show him a recent model that he says would meet his needs. You could make a good commission on this sale. You know that next week your firm will be offering a brand new machine with a special price rebate that would be a better deal for this customer. The commission on the new product however, would be less than that on the new machine.

How likely are you to tell the customer about next week's sale?

2. Economics conditions have hurt demand, and your company has decided to cut production. The employees are a team and you cannot reduce their numbers. You are considering two options: (1) You can keep production output constant for ten months, and then shut down the factory and lay off all your employees for two months, or (2) You can run the factory for the whole year at a lower level of output without laying off any employees. Employee wages would be the same under both options and so the second option would cost the company $15 \%$ more.

How likely are you to run the factory for the whole year?

3. Your main product has been redesigned, and required modified raw materials in the production process. Your main supplier reveals that he would be unable to meet the deadline for the launch of your redesigned product. There would be a delay of two months, before he could ship the modified raw materials. Another supplier offers an immediate supply of the raw material, but only if you sign a three-year exclusive contract with him. Your old and trusted supplier probably would go out of business if you change suppliers.

How likely are you to change suppliers?

4. Your college recruiter presents to you two job candidates, one male and one female, for a computer programming position. Both meet the minimum job requirements, but the female has extensive computer experience compared to the male applicant. Due to her experience, the female probably would do a better job. You have never employed a female computer programmer before and you suspect that your clients would prefer working with a male programmer.

How likely are you to hire the female applicant?

5. A client offers you a contract for a very large order if you guarantee to deliver the shipment within two weeks. There is no possible way to deliver within two weeks. You know that a one-week delay in the shipment will not cause your client any real harm, although he will complain a lot.

How likely are you to guarantee the shipment to obtain the contract?

6. You go on a long business trip with your immediate supervisor. Shortly after your return you accidentally notice his expense claim report on his desk. You see that he is claiming about twice the amount he actually spent on the trip. One week later the accounting office telephones you and asks if you can give verbal confirmation that your supervisor actually spent the money he is claiming for the trip.

How likely are you to conceal that your supervisor is claiming more money than he spent?

7. One of your foreign subsidiaries is having personnel problems in one of its factories. Some female 
employees in the factory are protesting because they get paid $20 \%$ less per hour than male workers in the factory. They argue that the male and female workers do comparable work and thus should be paid the same wage. The subsidiary is located in a country which has no laws regarding this matter and where females are customarily paid less than males.

How likely are you to increase the wages of the female workers?

8. One day you hear a rumor that a competitor has a new product feature that will make a big difference in sales. That evening, a business associate tells you that he can obtain a copy of the secret design plans for the new product feature. He asks you if you would like him to send you a copy.

How likely are you to accept the plan?

9. You have just been transferred to one of your company's factories. You see an employee pouring used solvent and cleaning solutions down a drain and you tell him to stop immediately. You know that it is illegal to dispose of harmful chemical through the public sewers. You tell the plant manager, your superior, about the employee's illegal act. He tells you not to worry. He says that the plant has disposed of its chemicals through the drains for the last ten years and no has ever found out about it.

How likely are you to reveal the plant manager's actions to top management at company headquarters?

10. At your company's annual social event you overhear several of your production workers commenting that they have cramped hand muscles because of the design of the tools they use at work. The following week you contact an expert, who tells you that ergonomically designed tools would significantly reduce the discomfort experienced by the workers. The cost of the new tools is quite significant and production output would not be affected by the change in tools.

How likely are you to buy ergonomically designed tools?

11. You have recently purchased some new automated equipment which will displace 20 of your employees. You have the option of laying off these employees or retraining and absorbing them in another factory. The cost of retraining and absorbing the employees in your factory will be $20 \%$ more than the cost of a generous severance package.

How likely are you to offer the retraining to the displaced employees?

12. A client invites you to a coffee shop to discuss the written proposal for a major project that you have submitted to him last week. He indicates that your proposal is excellent but that he has some difficulties with the price you quote for the project. He leaves to go to the washroom, leaving you alone or a short while. Next to your proposal on top of the counter are the written proposals from your two main competitors. You know that it would take only a few seconds to open the rival proposals to see what prices they quote.

How likely are you to look inside your competitors' written proposals?

13. One of the managers at your firm suggests a method of getting prices reductions from your suppliers. The method is to demand a $7 \%$ reduction or else threaten to go to another supplier who is offering a $10 \%$ reduction. This is not true, but the manager predicts that the supplier will negotiate. and that $4 \%$ price reductions can be expected. You have used the same suppliers for a long time and have good relations with them, but you have never negotiated with them in this way before.

How likely are you to accept this method of negotiating with your suppliers?

14. The manufacturing machinery used in your industry is suspected of causing eye damage to its operators. 
Safety equipment to prevent eye injury could be purchased by your firm at a significant cost. Your company has not been very profitable in the past two years.

How likely are you to purchase safety equipment?

\section{NOTES}

